\title{
Ten Years of the Central Italy Electromagnetic Network (CIEN) Continuous Monitoring
}

\author{
Cristiano Fidani1 ${ }^{1,2}$, Daniele Marcelli ${ }^{2}$ \\ ${ }^{1}$ Osservatorio Sismico “Andrea Bina”, Perugia, Italy \\ ${ }^{2}$ Central Italy Electromagnetic Network, Fermo, Italy \\ Email: c.fidani@virgilio.it
}

How to cite this paper: Fidani, C. and Marcelli, D. (2017) Ten Years of the Central Italy Electromagnetic Network (CIEN) Continuous Monitoring. Open Journal of Earthquake Research, 6, 73-88. https://doi.org/10.4236/ojer.2017.62004

Received: February 7, 2017

Accepted: March 14, 2017

Published: March 17, 2017

Copyright (c) 2017 by authors and Scientific Research Publishing Inc. This work is licensed under the Creative Commons Attribution International License (CC BY 4.0).

http://creativecommons.org/licenses/by/4.0/

(c) †) Open Access

\begin{abstract}
A test is being realised by means of a network of wide band electromagnetic detectors that continuously records the electric components of the electromagnetic field, ranging from a few of $\mathrm{Hz}$ to tens of $\mathrm{kHz}$. The network has been operating in central Italy for more than ten years. The recorded signals from this network have been analysed in real time as well as their power spectrum contents. Time/frequency data have been saved for further analysis. The spectral contents have evidenced very distinct power spectrum signatures in ELF band that increase in intensity when strong seismic activity occurs near the stations, for example, at the time of Amatrice $(M=6)$ and Norcia $(M=$ 6.5) earthquakes in 2016 when ten stations were operative, at the time of the Emilia $(M=6)$ earthquakes in 2012 when nine stations were operative, and at the time of the L'Aquila ( $M=6.3)$ earthquakes in 2009 when only two stations were operative. Strong signals were also detected during the moderate Ancona $(M=5)$ earthquake in 2013 and by the recently installed Avigliano Umbro, Città di Castello and Gubbio stations in the Umbria region, during small seismic swarms $(2<\mathrm{M}<4)$ between 2013 and 2014. CIEN is presently composed of 16 stations and collect data from a multidisciplinary instrumentation.
\end{abstract}

\section{Keywords}

Electromagnetic Network, Earthquake Forecasting, Vertical Conductivity, GPS Synchronization

\section{Introduction}

Over the last decade, major earthquakes have occurred throughout Italy, leading to deaths and extensive damage. Three of these earthquakes have reached the threshold of 6 , about one every three years, causing over six hundred deaths. 
Many reinforced concrete structures have collapsed. All this, despite repeated, appeals to build anti-seismic constructions and carry out restorations following stringent laws that were promulgated to avoid repeating the disasters of the twentieth century. Can the restoration of structures serve as a real solution for avoiding more Italian causalities? It is necessary but not sufficient, as has been proven over the last twenty years. Furthermore, this remedy would need many decades to be realised, failing to ensure the protection of today's population. Being so, a thorough study of all the physical phenomena that occur around the time of earthquakes should be carried out to verify the possibility of moving inhabitants away from buildings that are considered non-anti-seismic during a seismic crisis, but before the occurrence of destructive shocks. Over the last ten years many moderate earthquakes, $M>3.5$ [1], have occurred in Italy which did not produce major damages or casualties but were useful for testing different physical parameters.

CIEN is presently composed of 16 stations including Norcia and Colfiorito which were made operative at the end of 2016, in Perugia province. Trasacco and Urbino Stations were made operative in March and May 2015, in L'Aquila and Pesaro-Urbino provinces, respectively. Pozzuolo del Friuli (Udine) and Camerino (Macerata) Stations were made operative in Spring 2014. The Gubbio (Perugia) Station started to record from the beginning of 2014 but from January 2015 has been out of order, so as the Pozzuolo del Friuli Station. Then Gubbio was substituted by Urbino (Pesaro) Station and Pozzuolo del Friuli restarted November 2016. A CIEN update is shown in Figure 1. The first CIEN station began operating near the city of Fermo, in the Marche Region in 2006, after four years of experimentation, with several types of low frequency wide band amplifiers. The Fermo station was uniformed in 2010 to the other CIEN stations by a couple of ELF $(4 \mathrm{~Hz}-1 \mathrm{kHz})$ inverting amplifiers, where electrodes were set perpendicularly to each other and oriented along N-S and E-W directions. A second station began operations in Perugia, in the Umbria Region in 2008. From summer 2010 onward, two other stations began operating in the city of Zocca, near Modena, in the Emilia Romagna Region in August 2010, and in Capitignano, near L'Aquila, in the Abruzzo Region in September 2010. In January 2011, the Chieti Station was activated at the University of Gabriele D'Annunzio, in the Abruzzo Region. In February 2011, the Siena Station began recording in the Tuscany Region. In March 2011, the Fagnano Station, near L'Aquila, in the Abruzzo Region, was activated. From October 2011, the Contigliano (Rieti) Station has been activated in the Lazio Region. In May 2012 the Torre Pellice, near Turin, Station began the same type of recording. From April 2011, all of stations were updated to record VLF (1 - $25 \mathrm{kHz}$ ) signals, while in June 2011 onward, a frequency band extension test started at the Chieti Station which is also operative in the ULF $(0.04-4 \mathrm{~Hz})$ and Low Frequency band has its own jpeg file. From the summer 2012, four stations were not operative because of technical problems: Torre Pellice, Fagnano Amiterno, Siena and Capitignano Stations. All 16 stations recorded in ELF band with a range of 4 to $1000 \mathrm{~Hz}$ and in VLF band. 


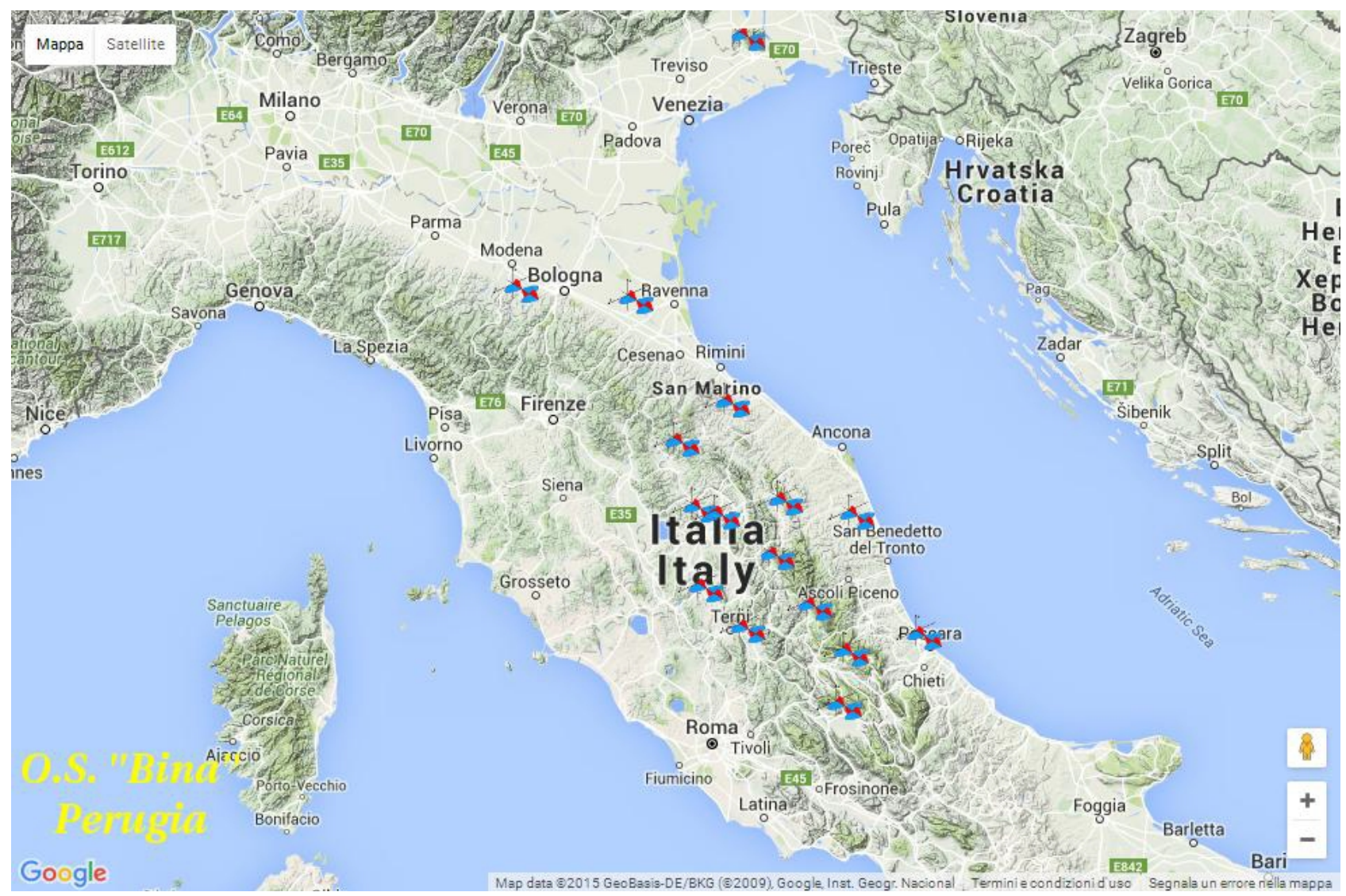

Figure 1. CIEN Stations operating in Italy as shown on a Google map from the Bina Observatory web site at http://www.binapg.it/.

with a range of 1 to $25 \mathrm{kHz}$ Whereas, four stations, Chieti, Fermo, Città di Castello and Urbino recorded also in LF in a range of 25 to $50-100 \mathrm{kHz}$.

Continuous long-term electromagnetic monitoring is necessary for obtaining reliable results regarding its correlation with seismic activity [2]. Characteristic ELF signals were monitored in relation to seismic activity in Fermo, Marche Region, Italy, from January 2006 and particularly before and after the L'Aquila earthquake in 2009 [3]. These signals were detected also during low seismic activity at the Perugia CIEN Station from October 2008, and in occasion of the Emilia earthquake [4]. ELF signals were also recorded by mean of txt files relative to six power supply harmonics and five Schumann resonances. Where there were both VLF and LF monitoring, there were also two txt files, one for each band. VLF and LF ranges have allowed detecting several sub-ionospheric signals by various radio navigation systems [3], which evident changes were not due to strong earthquakes [5]. CIEN began a multi-parametric monitoring after 2011, when Chieti Station supported terrestrial currents and magnetic component recordings. Magnetic recordings were also realised in other three stations of Città di Castello, Avigliano Umbro and Norcia. Vertical conductivity recordings started in Perugia Station after 2013, and then it was exported in Fermo, Chieti, Camerino, Città di Castello, Avigliano Umbro, Urbino, Colfiorito and Norcia. Fermo and Fagnano Stations were equipped with gamma detectors. Contigliano Station was equipped with cameras for transient luminous phenomena in at- 
mosphere. Finally, meteorological stations were also used in several positions and underground thermometer and hygrometer started to collect data at Fermo Station.

The objective to verify a correlation between electrical signals and earthquakes has been fixed with a program of a systematic electric field monitoring. A low cost technology permitted for the building of a dense network in Central Italy in only a few years. It was made up of electrodes which were innovative sensors with respect to other systems measuring potential differences. However, electric field monitoring was carried out into the atmosphere, so it recorded all electric meteorological phenomena. Therefore, it was necessary to take into account other geophysical parameters to found a possible model linking electrical and seismic activities.

\section{Stored Data by CIEN}

The sensors are composed of electrode wires with electronics that prepare the signals and are positioned into the atmosphere at the positions of CIEN Stations. Electronics are connected to a PC for their power supply. The pre-analyses for each of the stations are saved in the HD. All the station electrodes have one wire positioned toward the N-S while the second wire runs E-W. These two wires are covered by insulating sheaths, as well as their supports that keep them off the ground. All electrodes have two long thin wires each from $\mathrm{l}=10 \mathrm{~m}$ to $\mathrm{l}=20 \mathrm{~m}$ in length and from $\mathrm{s}=0.5 \mathrm{~mm}$ to $\mathrm{s}=1 \mathrm{~mm}$ in thickness. Each couple of wires are perpendicular to each other and horizontally fixed at about $\mathrm{h}=8-10 \mathrm{~m}$ off the ground. Sensors are positioned outdoors as they are responsible for picking up electromagnetic signals into the atmosphere. Signals are induced on the electrodes, both by capacitive and inductive effects [3]. Signals are distinguishable by taking into account the noise levels which depend principally on meteorological activity, both global and local. These activities influence the seasonal and daily noise, respectively. ELF is unusable during thunderstorms, while VLF and LF are less influenced by meteorology [6].

The signals are registered by PC audio cards in stereo mode for both direction electrodes with a 16 bit A/D conversion, permitting a dynamic range of about 96 $\mathrm{dB}$. This is necessary as weak signals start at $-100 \mathrm{~dB}$, while meteorological phenomena can increase the signal amplitudes up until $-20 \mathrm{~dB}$. Spectrum Laboratory free software (at http://www.qsl.net/dl4yhf/spectra1.html) is used to fix the recording parameters and to analyse the signals utilising Fast Fourier Transform [7]. Fast Fourier Transform is calculated for both the channels at every 4.096 seconds with an input size of 16,384 and a Hann window function. The power amplitude range is chosen to cover $-106 \mathrm{~dB}$ to $-10 \mathrm{~dB}$ with the too_many_colours legend, which allow drawing about 20 different colours and shades as well as evaluate $5 \mathrm{~dB}$ amplitude differences. A quantitative amplitude estimation of some previously observed signals requires calibration, as the signal transfer functions which occur in this system are not known. This calibration can be realised in different ways, taking into account electromagnetic theory, as well as 
experimental methods [3].

For every station, data are available in three formats: wave files for recovering the complete time evolution of the signals (active up to 2015), jpeg files for saving the dynamic spectra of the signals and txt files where the times, dates and amplitudes of all the signal transmitters are recorded. Each specific band has its own jpeg file. Where there are both VLF and LF monitoring, there are also two txt files, one for each band. Colour images of the spectrograms are saved with a resolution of $1280 \times 1024$ pixels, where the horizontal axis describes the time, with the help of vertical dotted lines every five minutes. Vertical axis of spectrograms describes the frequency. The scale is chosen to be linear for the VLF and logarithmic for the ELF bands. Data is stored in DVDs for future analysis.

The CIEN instruments for VLF and LF, compared to radio receivers, have some advantages. First, it uses a wide band amplifier, and just one instrument allows to observe many transmitters simultaneously. Second, a software solution can be used to separate the different transmitter signals. So, in VLF band transmitters are identifiable [3], see Figure 2 bottom: Alpha $500 \mathrm{~kW}$ radio navigation system in Novosibirsk, Krasnodar and Khabarovsk, Russia at 11.905 kHz, 12.649 $\mathrm{kHz}$ and $14.881 \mathrm{kHz} ; 400 \mathrm{~kW}$ in Rosnay, France at $15.1 \mathrm{kHz}$ and $21.75 \mathrm{kHz} ; 100$ $\mathrm{kW}$ in Matotchkinchar, Russia at $18.1 \mathrm{kHz} ; 400 \mathrm{~kW}$ in Anthorn/Skelton, England at $19.6 \mathrm{kHz}$ and $22.1 \mathrm{kHz} ; 400 \mathrm{~kW}$ in Saint-Assise, France at $20.9 \mathrm{kHz} ; 800$ $\mathrm{kW}$ in Rhauderfehn, Germany at $23.4 \mathrm{kHz} ; 1000 \mathrm{~kW}$ in Culter, Maine at 24.0 $\mathrm{kHz}$ and $192 \mathrm{~kW}$ in Seattle, Washington at $24.6 \mathrm{kHz}$. While in LF band: Bafa, Turkey, 26.7 kHz; Kaliningrad, Russia, 30.3 kHz; Niscemi, Italy, 45.9 kHz; Maraton, Greece, 49.0 kHz; Irkutsk, Russia, 50.0 kHz; Anthorn, England, 60.0 kHz; La Règine, France, 62.6 kHz; Kerlouan, France, 65.8 kHz; Moscow, Russia, 66.6 $\mathrm{kHz}$;Lintong, China, $68.5 \mathrm{kHz}$; Prangings, Switzerland, $75.0 \mathrm{kHz}$; Mainflingen, Germany, $77.5 \mathrm{kHz}$; Inskip, England, $81.0 \mathrm{kHz}$.

Recently, from October 2016, a synchronization of VLF signal was realised at Fermo Station by using a special GPS [8]. The sampling system realised by a PC sound card can be synchronized by mixing the signal with an appropriate GPS output clock. NAVMAN output clock is a $10 \mathrm{kHz}$ square wave that is precisely aligned with the UTC second, see Figure 2. Synchronization of VLF signal permits to precisely measure phases of radio Broadcasts.

\section{Signals Recorded by CIEN}

After the Emilia earthquake in 2012 a strong earthquake $M=5$ struck the Adriatic sea a few kilometres from the shore near the city of Ancona, Marche Region, on July 21, 2013. According to reports received by EMSC, the main shock occurred at 01:32 UTC (local time Sunday, July 21, 2013, at 03:32) and lasted for 10 - 12 seconds. The depth of the shock was reported as $5 \mathrm{~km}$, near the villages of Numana and Sirolo. During the same year, a moderate earthquake swarm started in the Pietralunga area, $35 \mathrm{~km}$ north of Perugia on March 24, 2013, and it migrated to the Gubbio area, $30 \mathrm{~km}$ NE of Perugia, in December 2013. Another moderate seismic swarm started at the half of March 2014, in the Massa Martana 


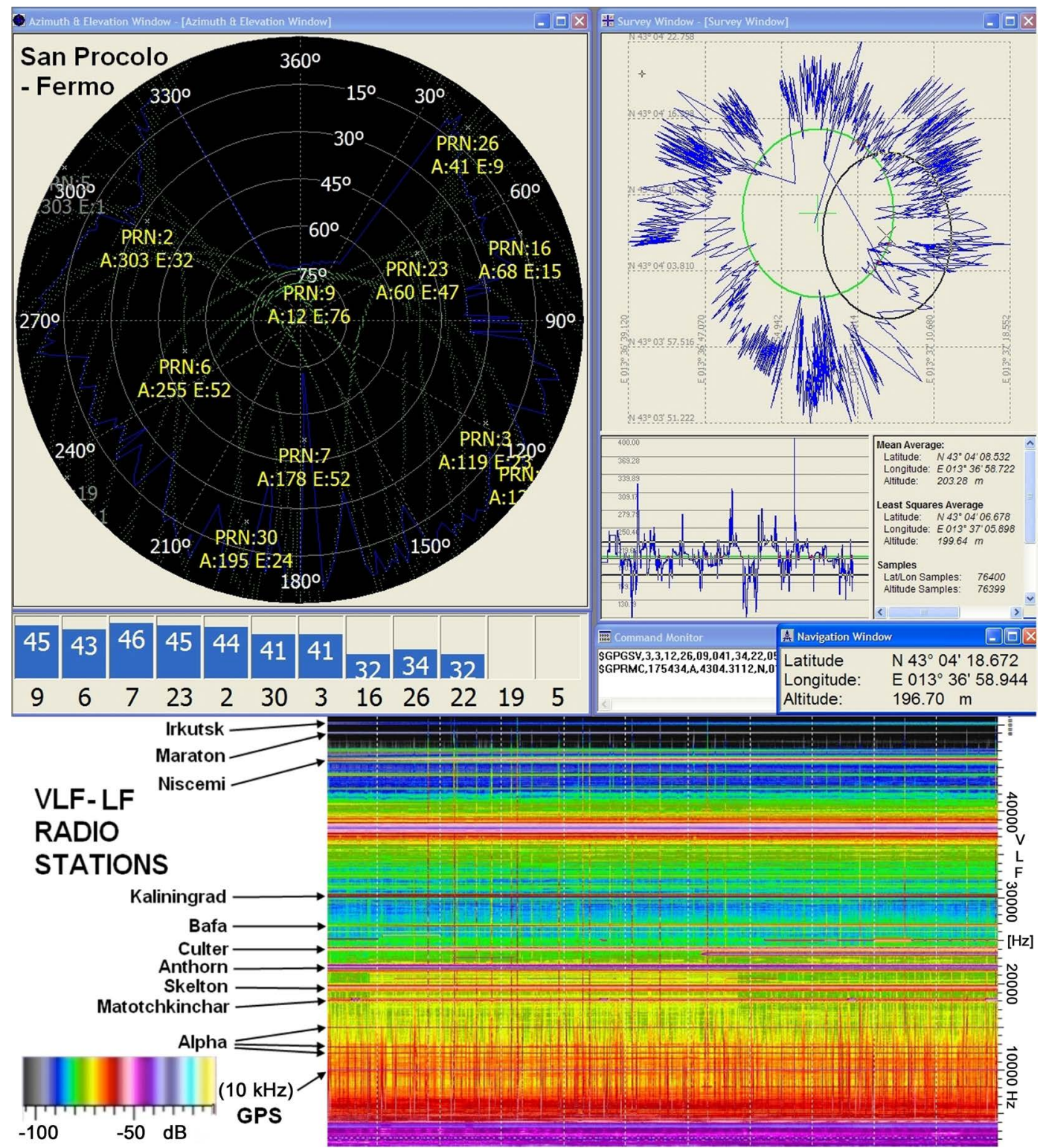

Figure 2. GPS system at the Fermo Station after October 2016, an example of satellite positioning and station coordinates calculated by GpsView software on the top; a spectrogram was shown where GPS signal and VLF radio transmitters were indicated on the bottom.

area, $45 \mathrm{~km}$ south of Perugia, migrating to the Colfiorito area, $35 \mathrm{~km} \mathrm{SE}$ of Perugia, in April 2014. The swarms occurred at shallow crustal levels from 4 to $12 \mathrm{~km}$ in depth. They covered the area over the Alto Tiberina Fault, a low angle normal fault that acts as a basal seismic detachment and accommodates extensional deformation together with a complex normal fault system that is located in its hanging wall [9]. The structure bounds the western side of the upper Tiber Quaternary basin, and it is about $70 \mathrm{~km}$ long, dipping from $15^{\circ}$ to $20^{\circ}$ ENE [10]. It is clearly evident in the CROP03-NVR seismic reflection profiles [11] [12] [13]. The micro-seismicity associated with this system of faults is probably triggered by frictional instabilities that are created by fluid over pressure, while the most of the extension along the fault is accommodated by aseismic slip and creep [14]. 
The possible occurrence of moderate-to-large earthquakes generated by low angle normal fault is an open question [15]. Thus, it is relevant in terms of seismic hazard. In the tectonic setting of the Apennines, a seismic migration episode along the strike of a fault system or along a preferred direction was observed during seismic sequences of the Colfiorito earthquake in 1997 [16]. Over the past 5 years, characteristic ELF signals were detected at the Perugia station as well as in the recently installed Avigliano Umbro, Città di Castello and Gubbio stations.

ELF signals were recorded by the N-S antenna in Avigliano Umbro on July 19, 2013, at about 1:00 LT, is shown in Figure 3 on the left. Its oscillation covers a similar frequency range as those already reported in other publications [3] [4]; between 50 and $100 \mathrm{~Hz}$. Moreover, the duration of the signal was about $7 \mathrm{~min}$, as well, other traces of it appeared hours before and after it. The frequencies of these signals increased at the beginning, but decreased towards the end. However, no time correspondence was observed between the signals recorded at all of the stations, indicating that they were of local origin. Additionally, their times did not coincide with the earthquake time. Moreover, the signatures almost always appeared on only one electrode of each station and when appearing on both electrodes, the two signatures were always different. Strong ELF signals were also recorded by the Fermo and Perugia Stations during the weeks prior to the July 21, 2013, Ancona earthquake. These oscillations had frequencies ranging between 40 and $200 \mathrm{~Hz}$, they also often started and ended at lower frequencies. Moreover, the duration of the signals ranged from few minutes to several hours. The strongest intensities were recorded on the days before and after the main shock, with amplitudes greater than $1 \mu \mathrm{V} / \mathrm{m}$.

The sensor for vertical conductivity installed at the Perugia Station was activated on the top of the "Andrea Bina" Observatory at the beginning of April on 2013. It recorded a clear signal from about 30 minutes to 5 minutes before the Ancona shock, then the signal suddenly disappeared, see Figure 3 on the right.

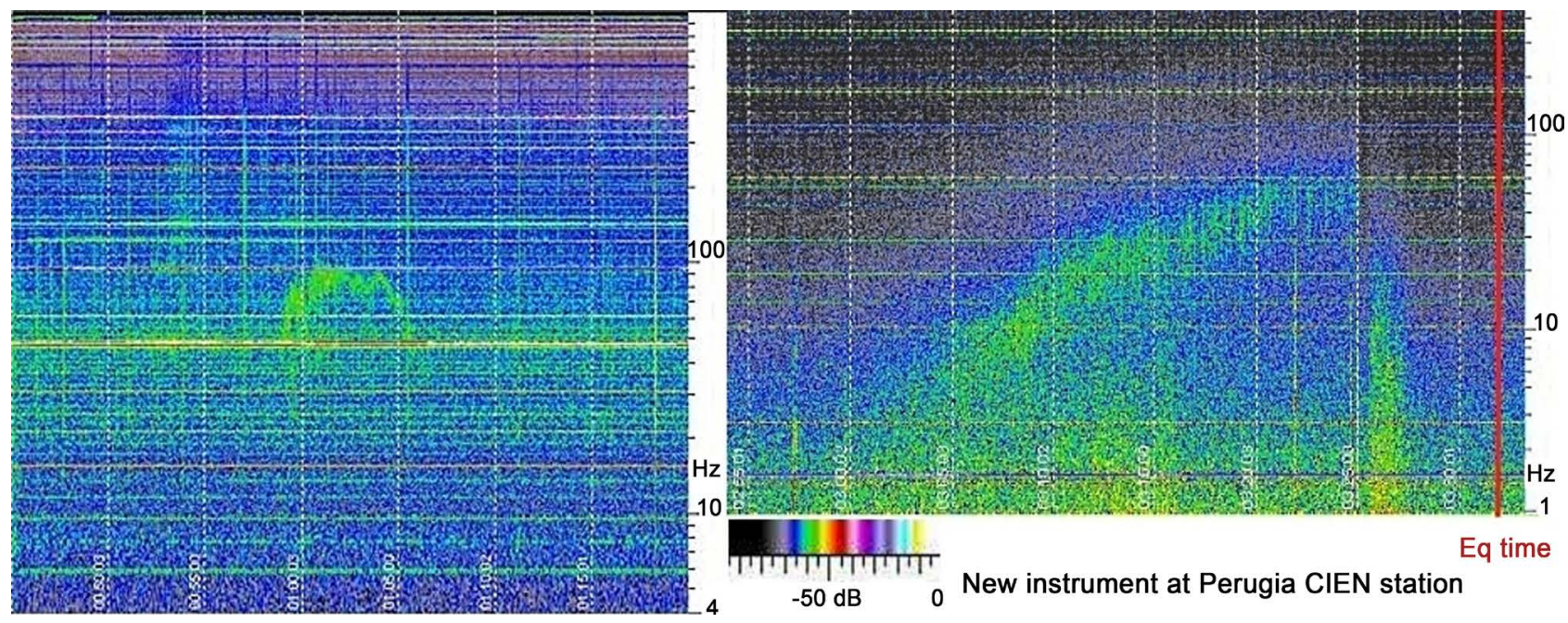

Figure 3. The ELF signals recorded at the Avigliano Umbro Station on July 19, 2013, N-S antenna, on the left; the electric signal observed by the new instrument at the Perugia Station a few minutes before the shock. 
The new sensor recorded an electric oscillation which had probably stated under $10 \mathrm{~Hz}$ and increased up to $200 \mathrm{~Hz}$, with a frequency width of about $50 \mathrm{~Hz}$. The electric vibration power intensity reached a signal to noise ratio of about $15-20$ $\mathrm{dB}$ in the $50-100 \mathrm{~Hz}$ range. Disappearing, the signal covered the whole range of $10-200 \mathrm{~Hz}$ in a few seconds.

Electrical oscillations, such as those reported in connection with the 2009 L'Aquila earthquake [3] were also detected at the Perugia station during moderate seismic activity. Specifically, electrical oscillations were recorded on many occasions where $\mathrm{M}=2.8-3.7$ in the Pietralunga territory. The pattern recorded from the S-N electrode lasted from a few minutes up to two hours, and concerned electrical oscillations between $40 \mathrm{~Hz}$ and $350 \mathrm{~Hz}$. The electrical oscillation intensities observed during moderate seismic activity near the Perugia station ranged between $-70 \mathrm{~dB}$ and $-55 \mathrm{~dB}$. To verify if observed electrical oscillations could have been influenced by the meteorological precipitation, data from the meteorological stations in Perugia were retrieved. Precipitation events were also recorded in ELF data at the Perugia station, as water drops are charged and produced intense signals on spectrograms. These data were used to label ELF oscillations occurring during rainfalls. Finally, ELF data were analysed from April 2013 to April 2014 for a total of 9480 hours of records, producing about $146 \mathrm{~Gb}$ of data. Spectrograms were prepared to better localise ELF anomalies, compared to electromagnetic noise. A scale of colours, corresponding to $5 \mathrm{~dB}$ variations in power spectral amplitudes, was sufficient to distinguish the oscillations. Being so, all anomalies $>5 \mathrm{~dB}$ above noise were collected. In order to verify when meteorological phenomena could have produced the electric oscillations, rainfall data were superimposed on ELF data. Moreover, electrical oscillations occurring less that 30 minutes from rainfall events were excluded from the analysis. Strong electrical oscillations were identified from records taken a few hours or days before the moderate shocks. A summary of recordings from the Perugia station of both electrodes, N-S and E-W, over years 2013 - 2014 is shown in Figure 4. To verify an association between earthquakes electric oscillations, seismic activity in a radius of $30 \mathrm{~km}$ and $70 \mathrm{~km}$ around Perugia were plotted on the same graph and shown in red.

An increase in the seismic activity also occurred in the Massa Martana area since de middle of March 2014 and on March 26, 2014, with a shock of M = 3 [1]. The swarm epicentre was about $45 \mathrm{~km}$ south of the Perugia station that started to record data in October 2008. Likewise, the epicentre was about $10 \mathrm{~km}$ east of the Avigliano Umbro station, which started to record data in June 2013. Two shocks with a magnitude $\mathrm{M}=3.1$ struck the same area seven days later, on April 2, 2014. The seismic swarm migrated to the Colfiorito area on April 15, 2014, with a shock of $M=3.3$ and other smaller seismic events [1]. Clear signals were detected at the Avigliano Umbro Station a few hours before the two strongest shocks occurring in Massa Martana on March 2014. The unusually clear electric disturbances recorded before the second moderate shock are shown in Figure 5. This figure shows a 3 hours spectrogram of vertical conductivity 


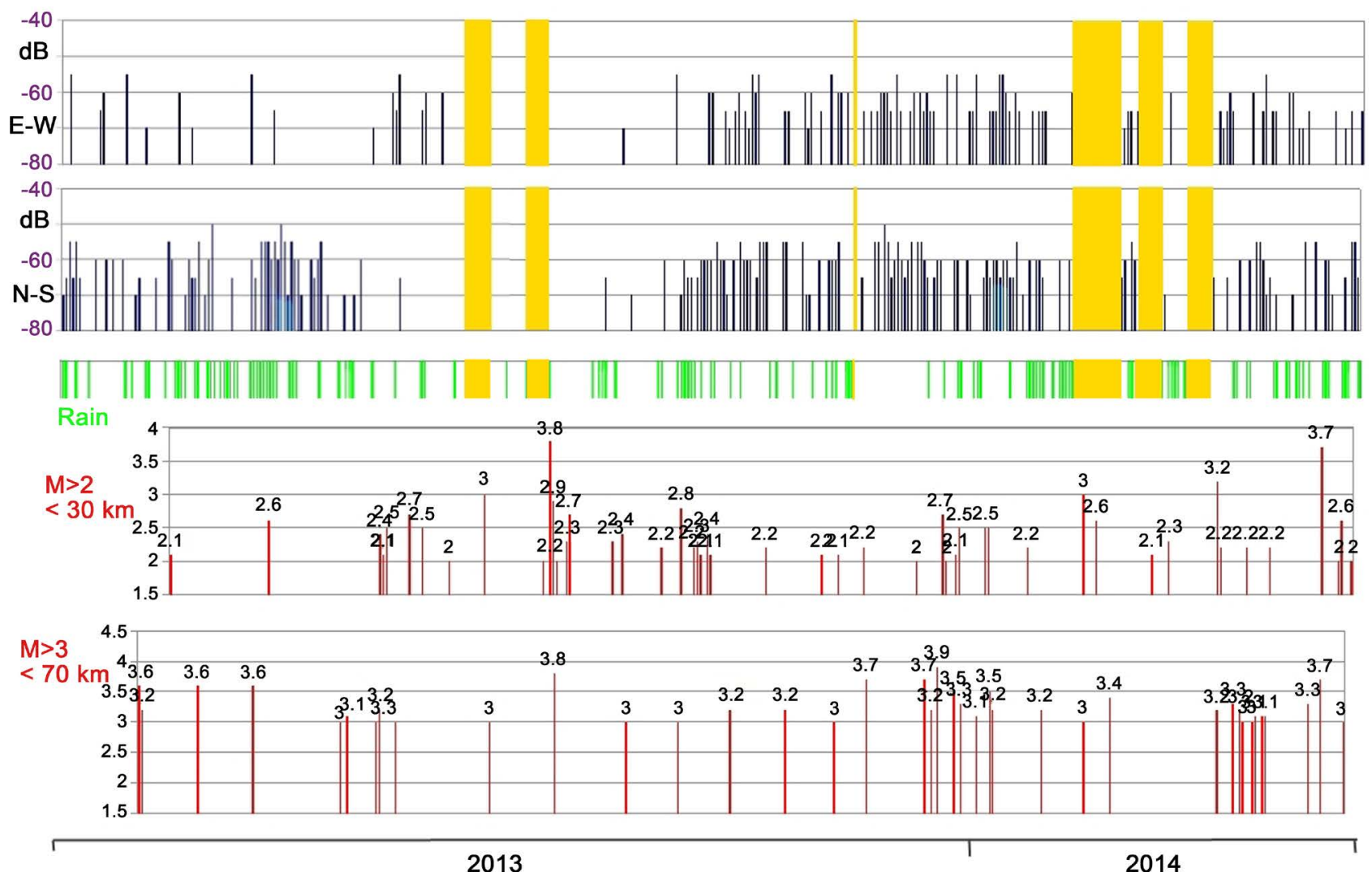

Figure 4. ELF oscillation intensities recorded from the beginning of April 2013 to the end of April 2014, are shown on the top panel; yellow areas indicate lost data; green bars under ELF oscillations indicate rainfall detected by the Perugia station; the black bars indicate the electrical oscillations occurred on E-W and S-N directions; the red bars indicate the seismic events of $\mathrm{M}>2$ occurred inside a $30 \mathrm{~km}$ radius from the station and finally the seismic events of $M>3$ occurred inside a $70 \mathrm{~km}$ radius.

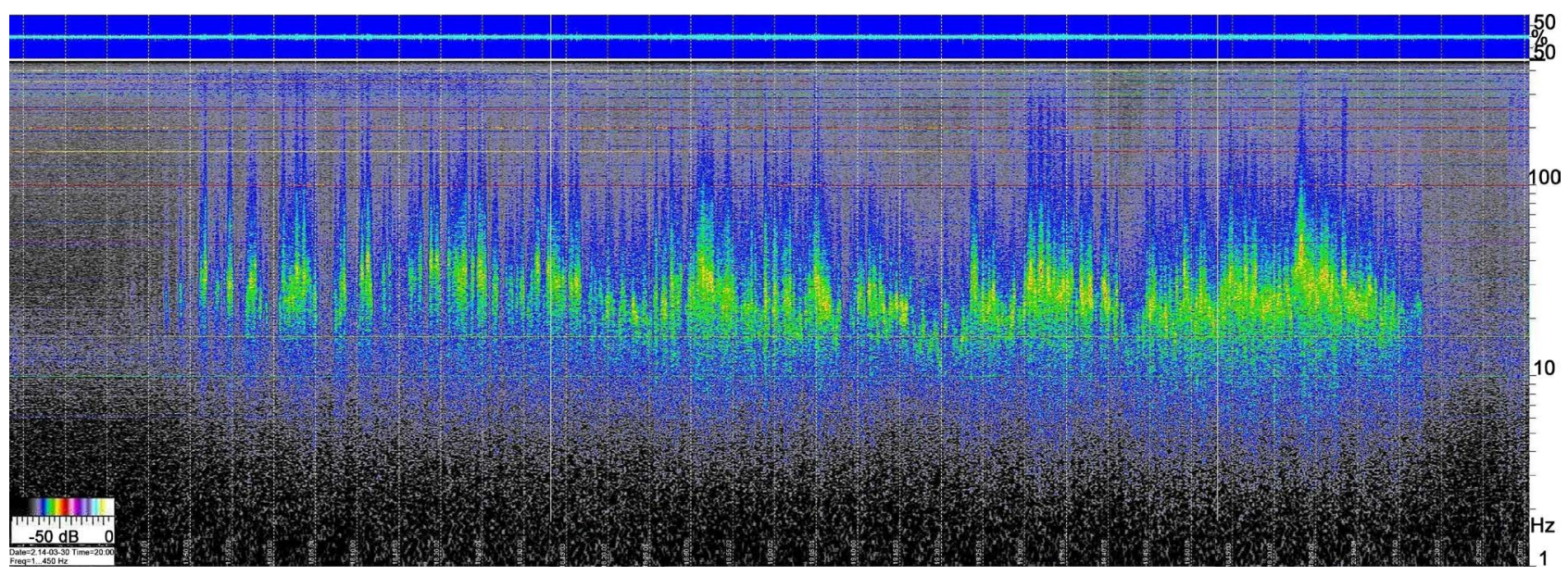

Figure 5. The ELF electric oscillations recorded at the Avigliano Umbro station on March 30, 2014, are shown; the oscillations lasted 150 minutes and followed an irregular pattern between $10 \mathrm{~Hz}$ and $100 \mathrm{~Hz}$ with a relative magnitude of up to $-50 \mathrm{~dB}$.

variations recorded at the Avigliano Umbro station. The spectrogram frequency range is $1-450 \mathrm{~Hz}$. The electrical oscillations range between $10 \mathrm{~Hz}$ and $100 \mathrm{~Hz}$, following a continuous and irregular path. The total time of the phenomena was about 150 minutes, with maximum intensities $25 \mathrm{~dB}$ above the noise power. A similar phenomenon was also observed before the first moderate shock. No sim- 
ilar oscillations were recorded on the vertical conductivity by other CIEN stations during the same period. The day before the moderate shock of $\mathrm{M}=3.3 \mathrm{in}$ the Colfiorito area, a signal of $-55 \mathrm{~dB}$ was also recorded at the Perugia station along the E-W electrode, see Figure 6. This electrical oscillation lasted about one hour and had the characteristic shape of an arc, as described in previous publications [3]. This signal was very well-defined in frequency but had a very irregular pattern, similar to past cases.

For what concerns vertical air conductivity measured in connection to Amatrice event, its variations at different frequencies were sampled far from the power electrical distribution harmonics. An example recorded at the Fermo Station from about two weeks before the Amatrice earthquake is reported in Figure 7 top. A set of conductivity variations occurred between August 17 and 19, 2016, and one peak occurred about seven hours before the main event indicated by a vertical red line. Electric field harmonics from the electrical power distribution were also monitored to detect variations linked to variations of dispersion currents through the ground. Figure 7 middle, shows the fifth harmonic from about two weeks before the main shock of Amatrice evidencing strong variations between August 17 and 19, 2016, and then followed by a marked increase in daily oscillation starting from August 22, 2016. VLF radio waves are sampled at many of the CIEN stations. The Fermo Station was able to sample radio broadcast up to $50 \mathrm{kHz}$ but the only radio transmitter which sub-ionospheric channel goes near the Amatrice epicentre was from Niscemi, Sicily, transmitting at about 45 $\mathrm{kHz}$. The variations in wave amplitude for the Niscemi transmitter are reported in Figure 7 bottom, from about two weeks before the main shock in Amatrice. This type of monitoring was recently made uninfluenced from meteorological activity by a special algorithm running at the Fermo and Perugia Stations, it consisted in subtracting meteorological contribution to electromagnetic intensity due to lightning activity. Two weeks of data preceding the Amatrice earth-

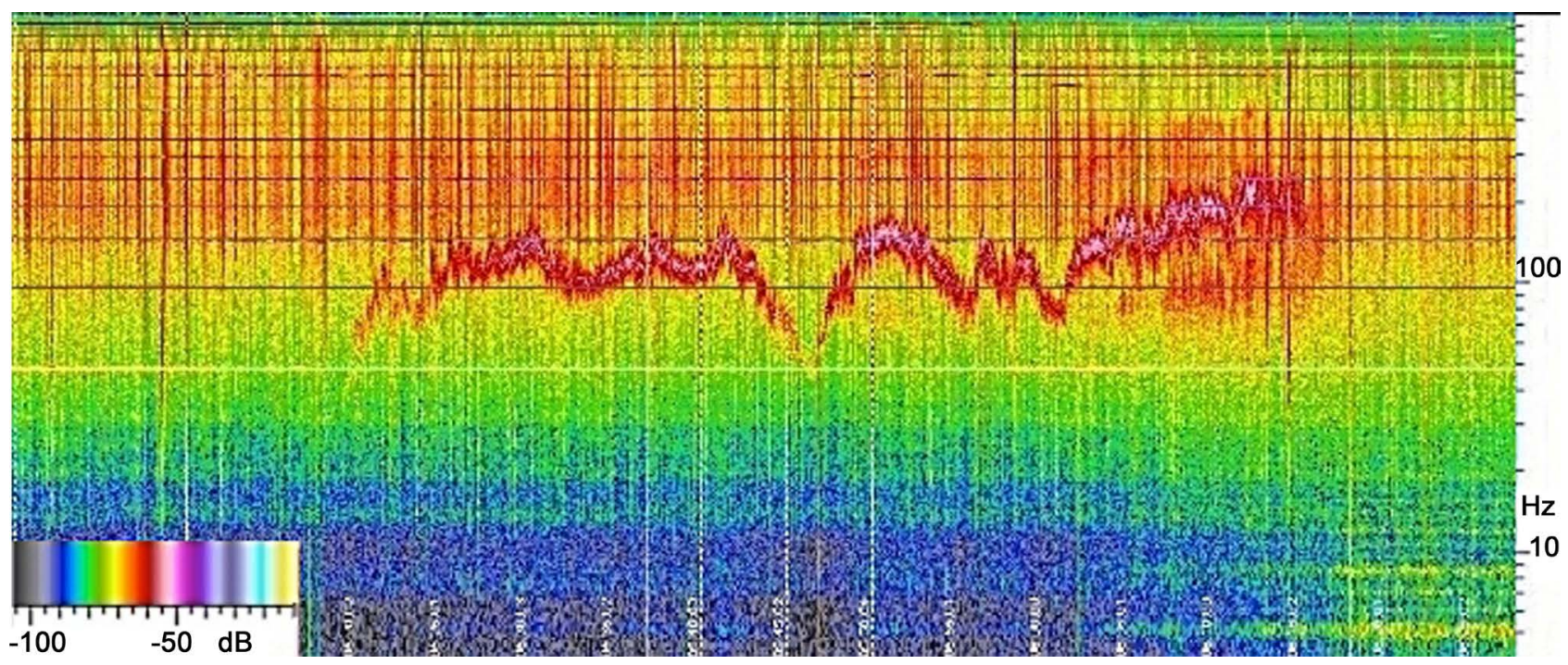

Figure 6. The strong horizontal ELF electric oscillations recorded at the Perugia Station on April 15, 2014, local time 5:00 - 6:30 (horizontal axis); the vertical axis describes the frequency in a logarithmic scale. 

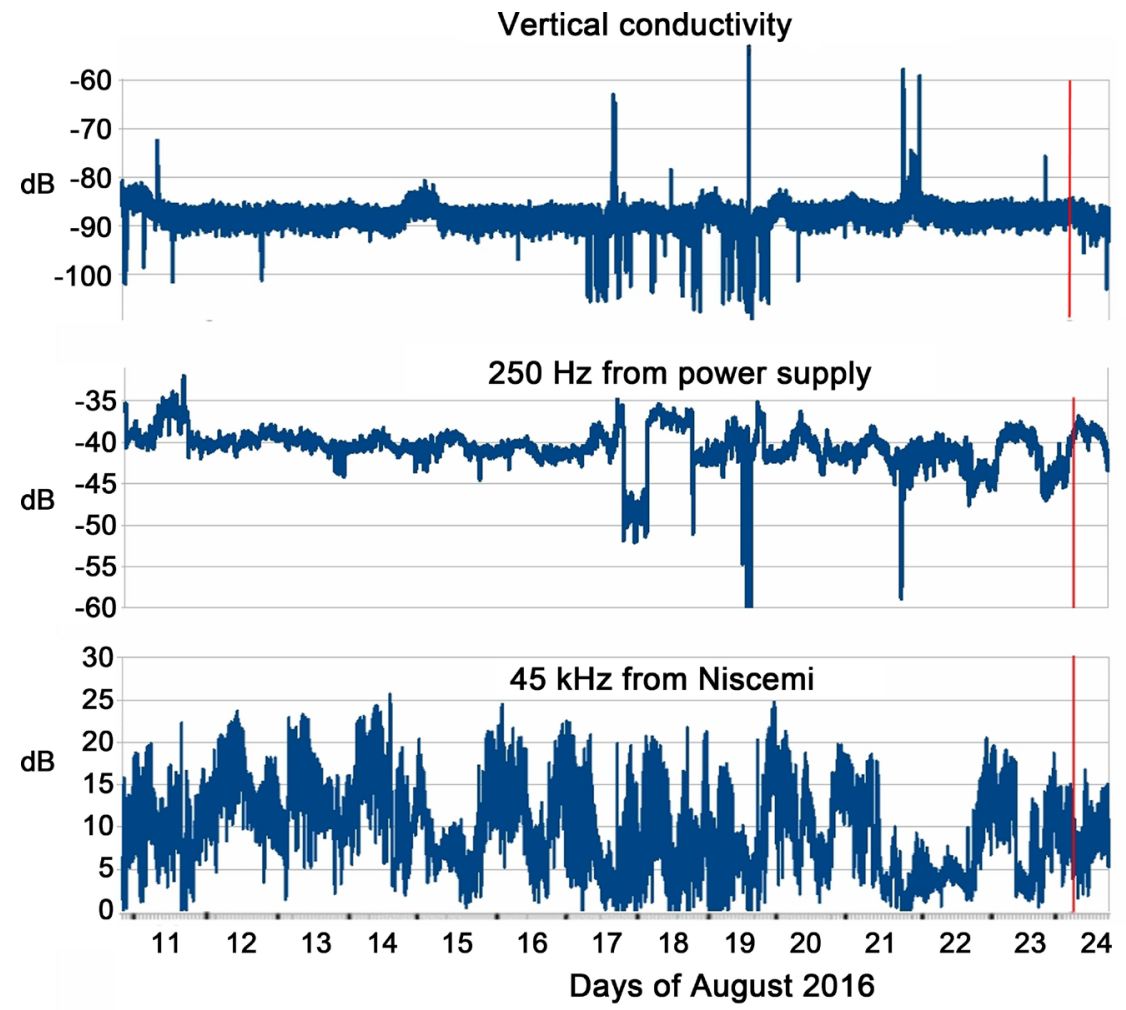

Figure 7. Vertical conductivity variations, fifth power distribution harmonic and Niscemi radio wave recorded at the Fermo Station after August 10, 2016.

quake, Figure 7 bottom, evidenced a strong amplitude depletion on the night between August 21 and 22, 2016, and a minor amplitude depletion on the night between August 14 and 15, 2016.

\section{Magnetic Counterpart Absence of ELF Signals, a Discussion}

From February 5, 2015, a magnetic loop was installed at the Avigliano Umbro Station in order to detect magnetic components of electric oscillations at locations where frequent ELF anomalies had been recorded. In fact, two magnetic loops had already been recording near two other CIEN electrodes in the Chieti and Città di Castello Stations, from January 2012 and July 2013 respectively; no magnetic signals have been recorded up to now simultaneously at ELF electric oscillations. All the magnetic loops of $1 \mathrm{~m}$ of diameter were shielded from electric fields and placed inside the stations, arranged so to detect the magnetic field variations in the north-south direction. The magnetic signals have been amplified to be registered using a sound card as well as electric signals. The magnetic field variations have been recorded and analysed in the same way as electric ones and have been reported on spectrograms together. This has been done to render a comparison more legible. For this analysis, no magnetic field variations were recorded during the numerous electric signals recorded at the Avigliano Umbro Station. This behavior can be explained by the model proposed for the source of the ELF electric oscillations [4]. In this model, rough spherical charge distributions could have formed in the atmosphere by expelled charged gases from the 
ground. The balancing electrostatic forces, due to air ions of net zero charge and external pressure could be responsible for spheroidal confined structures which are stable and oscillate [17]. But such symmetric structures, which oscillate radially, also create very small magnetic fields at a certain distance, due to the symmetry [18]. In a perfectly spherical symmetric charge distribution, the only direction that an electric field, magnetic field and radiation field can point to is radially outward from the centre of the sphere. However, in a radiation field the electric and magnetic fields must be transverse to the direction of motion, so this system also will not produce any radiation, or have a magnetic field. The electric field $E$, the charge density $\rho$, and the convective current density $v$ are linked by

$$
E=-\nabla \phi, \quad 4 \pi \rho=-\nabla^{2} \phi, \quad V=(\partial / \partial t \nabla \phi) / \nabla^{2} \phi
$$

where $\phi(x, y, z, t)$ is the time variable electric potential in the region $\mathrm{A}$ of the space, see Figure 8 . These choices, together with $\mathrm{H}=0$, automatically satisfy Maxwell's equations and describe an electromagnetic source, in an arbitrary volume, which only produces a static electric field in the region $\mathrm{B}$, outside the source region. Therefore, this model can explain why electric oscillations are not recorded by distant CIEN Stations [3], being the distance between them much greater the source dimension. For a true charged cloud which radially oscillates, the charge distribution decrease gradually with distance, and therefore a net electric field exists at a certain distance; to which a very small variable magnetic field is associated. Being that CIEN Stations are located near residential areas, where noise on magnetic detection is not very low, the possibility of revealing very low magnetic field variations is scarce. Furthermore, to increase the possibility of detecting a magnetic component associated to the recorded ELF electric oscillations, the magnetic loops should be installed in the same positions as the electrodes.

On the other hand, electric field oscillations were recorded by all 16 CIEN Stations also before many rainfalls without evidencing seismic activity. It has been reported that rainfalls are often preceded by electric ions variations in the atmosphere [19]. These observations suggested that electric oscillatory phenomena occurred together with air ion concentration fluctuations and/or meteorological instabilities. A model for a spherically symmetric and dynamically stable struc-

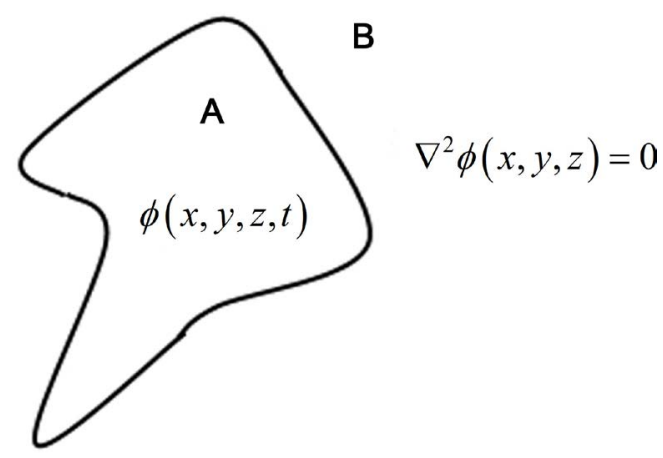

Figure 8. Regions A and B where electric charges are accelerating and electric potential satisfy Laplace's equation. 
tures has been proposed for the atmosphere by balancing electrostatic forces with air pressure [18]. The possibility of forming stable spherically symmetric charge configurations in the atmosphere has been the subject of many past investigations, which have been conducted with the aim of better understanding unusual atmospheric phenomena, such as ball lightning and earthquake lights [20] [21]. Thus, these charge configurations were potentially able to explain both observations of electric oscillations and luminosities in the atmosphere, depending on the charge density, with luminosities appearing when strong meteorological or seismic phenomena occurred [4]. However, in the atmosphere they were subject to probable far transport by wind. Thus, electric oscillations were monitored together with a meteorological station, to demonstrate if a causal relation with rain, wind direction and intensity were possible. Air ion counters [22] should be also useful to demonstrate the existence of charged clouds. Being so, this charged cloud model requires further investigation in order to determine if there were correlations between earthquakes and ELF oscillations, and between rainfalls and ELF oscillations.

\section{Conclusions}

Data recorded from the Perugia Station suggested that electric oscillations become slightly more intense and frequent during meteorological and seismically active periods, as recorded before and after several Pietralunga and Gubbio earthquakes. In fact, in these periods, the power spectra of the electrical oscillations become greater than other natural electromagnetic phenomena, such as the Schumann Resonances. CIEN observations into the atmosphere, near the Earth's surface, have discovered that sources of electrical oscillations induced in the electrodes were localised near the stations. Candidate pre-seismic oscillations in electric intensity were quantified and resulted being of the same order of the 2009 L'Aquila earthquakes [3]. High concentrations of ions at rock surface and variations of air conductivity have been reported when seismic activity increased [23]. Rainfalls have also been known to be preceded by electric charges in the atmosphere [19]. Moreover, the moderate seismic activity in the Umbria Region has been associated to degassing activity, which was related to the presence of over-pressurized fluids and to diffusion processes [24] [25] [26]. All of these observations have suggested the association among electrical oscillatory phenomena, air ions, ground gas emissions and/or meteorological instability.

Due to the general difference in temperatures between the ground and the atmosphere, when gas escapes from the ground it should produce atmospheric pressure differences. Pressure differences were also characteristics of meteorological oscillations. In the atmosphere they were responsible for air movements and, if air ions filled the atmosphere, pressure differences were also responsible for air ion movements. Consequently, electromagnetic waves were emitted with ion movements. However, the CIEN recording of electric fields was relatively stable oscillatory phenomena, indicating that a stable phenomenon of bounded source occurred. Thus, the electric charge clouds model due to balance between 
electrical and pressure forces [4] was able to explain electric oscillations also recorded during last events.

Magnetic data recorded at the Chieti, Città di Castello, Avigliano and Norcia CIEN Stations suggested that electric oscillations were characterised by magnetic intensities so small that, probably under the natural and anthropic noise levels, they were undetectable. The proposed model to explain electric oscillations [4] seemed to justify such small values due to the symmetric charge distributions supposed to be the sources of the signals. Such charged clouds model was able to justify the disappearance of electric field oscillations far from the source, thus justifying the absence of correlations among signals recorded by different CIEN stations evidenced in past studies. Vertical conductivity variations recorded by a new instrument installed at several CIEN stations were possibly produced by variations in concentration of air ions. Finally, the charged clouds model was in agreement with all the observations made by CIEN in occasions of both seismic and meteorologic events.

\section{Acknowledgements}

Author would like to thank Mauro Mariotti and Alexander Brucolini for kind cooperation in providing the GPS connection. Thanks to Alexander Brucolini, Dante Santoni, Adriano Nardi and Marusca Ambrogi for helping to assemble the new stations. Author would like to thank Riccardino (IKOYUJ) and Tommaso (IZ2OIM) of A.R.I. - Città di Castello, Francesco Stoppa, Massimo Orsini, and Giovanni Iezzi for kind cooperation in providing the magnetic data. Thanks to Sergio Tardioli for the publication of CIEN data into the Bina Observatory website. A particular thank goes to SARA electronic instruments and GESENU of Perugia for the hardware supplies.

\section{References}

[1] Bina, A. (2016) Seismic Observatory Data Collected between 2006 and 2016. http://www.binapg.it/

[2] Fidani, C. (2005) Ipotesi sulle anomalie elettromagnetiche associate ai terremoti. Libreria Universitaria Benedetti L'Aquila, L’Aquila.

[3] Fidani, C. (2011) The Central Italy Electromagnetic Network and the 2009 L'Aquila Earthquake: Observed Electric Activity. Geoscience, 1, 3-25. https://doi.org/10.3390/geosciences1010003

[4] Fidani, C. and Martinelli, G. (2015) A Possible Explanation for Electric Perturbations Recorded by the Italian CIEN Stations before the 2012 Emilia Earthquakes. Bollettino di Geofisica Teorica ed Applicata, 56, 211-226.

[5] Fidani, C., Albarello, D., Arcaleni, M., Martinelli, G., Siciliani, P.M., Tardioli, S. and Vannucchi, A. (2012) Emilia Earthquake: VLF Transmitters and ELF Signal from the Central Italy Electromagnetic Network (CIEN). Proceedings of the 31 th GNGTS, Potenza, 20-22 November 2012, 415-420.

[6] Fidani, C. (2011) L'Aquila Earthquake: Signal Intensities of Electric Field Anomalies. Proceeding of the 30 th GNGTS, Trieste, 14-17 November 2011, 363-365.

[7] DL4YHF (2011) Amateur Radio Software: Audio Spectrum Analyzer ("Spectrum 
Lab") 2.76. http://www.qsl.net/dl4yhf/spectra1.html

[8] NAVMAN (2002) Jupiter GPS Receiver, TU30-D400 Series Data Sheet, Revision A. http://www.sander-electronic.de/datasheet/gps/NAVMAN_Jupiter_11_Datasheet.p df

[9] Chiaraluce, L., Chiarabba, C., Collettini, C., Piccinini, D. and Cocco, M. (2007) Architecture and Mechanics of an Active Low-Angle Normal Fault: Alto Tiberina Fault, Northern Apennines, Italy. Journal of Geophysical Research, 112, B10310.

[10] Mirabella, F., Brozzetti, F., Lupattelli, A. and Barchi, M.R. (2011) Tectonic Evolution of a Low-Angle Extensional Fault System from Restored Cross-Sections in the Northern Apennines (Italy). Tectonics, 30, TC6002. https://doi.org/10.1029/2011tc002890

[11] Pialli, G., Barchi, M. and Minelli, G. (1998) Results of the CROP03 Deep Seismic Reflection Profile. Vol. 52, Società Geologica Italiana, Rome.

[12] Barchi, M., Minelli, R. and Pialli, G. (1998) The Crop 03 Profile: A Synthesis of Results on Deep Structures of the Northern Apennines. Vol. 52, Società Geologica Italiana, Rome, 383-400.

[13] Barchi, M., De Feyter, A., Magnani, M., Minelli, G., Pialli, G. and Sotera, B. (1998) Extensional Tectonics in the Northern Apennines (Italy): Evidence from the CROP03 Deep Seismic Reflection Line. Vol. 52, Società Geologica Italiana, Rome, 528-538.

[14] Collettini, C. and Barchi, M.R. (2002) A Low Angle Normal Fault in the Umbria Region (Central Italy): A Mechanical Model for the Related Microseismicity. Tectonophysics, 359, 97-115. https://doi.org/10.1016/S0040-1951(02)00441-9

[15] Wernicke, B. (1995) Low-Angle Normal Faults and Seismicity: A Review. Journal of Geophysical Research, 100, 20159-20174. https://doi.org/10.1029/95jb01911

[16] Catalli, F., Cocco, M., Console, R. and Chiaraluce, L. (2008) Modeling Seismicity Rate Changes during the 1997 Umbria-Marche Sequence (Central Italy) through a Rate- and State-Dependent Model. Journal of Geophysical Research, 113, B11301. https://doi.org/10.1029/2007jb005356

[17] Tennakone, K. (2011) Stable Spherically Symmetric Static Charge Separated Configurations in the Atmosphere: Implications on Ball Lightning and Earthquake Lights. Journal of Electrostatics, 69, 638-640. https://doi.org/10.1016/j.elstat.2011.08.005

[18] Heller, L., Biophys. Group, Los Alamos Nat. Lab., NM, USA, Ranken, D. and Best, E. (2004) The Magnetic Field inside Special Conducting Geometries Due to Internal Current. IEEE Transactions on Biomedical Engineering, 51, 1310-1318.

[19] Takahashi, T. (1972) Electric Charge of Small Particles (1 - $40 \mu)$. Journal Atmospheric Science, 29, 921-930. https://doi.org/10.1175/1520-0469(1972)029<0921:ECOSP >2.0.CO;2

[20] Singer, S. (1971) The Nature of Ball Lightning. Plenum Press, New York. https://doi.org/10.1007/978-1-4684-1866-8

[21] Tennakone, K. (2006) Ball Lightning Elusive Behaviour Depending on Proton Conductivity. Current Science, 90, 1247-1250.

[22] Kolarz, P., Miljkovic, B. and Curguz, Z. (2012) Air-Ion Counter and Mobility Spectrometer. Nuclear Instruments and Methods in Physics Research B, 279, 219-222. ttps://doi.org/10.1016/j.nimb.2011.10.061

[23] Freund, F.T., Kulahci, I.G., Cyr, G., Ling, J., Winnick, M., Tregloan-Reed, J. and Freund, M.M. (2009) Air Ionization at Rock Surface Sand Pre-Earthquake Signals. Journal of Atmospheric and Solar-Terrestrial Physics, 71, 1824-1834. 
https://doi.org/10.1016/j.jastp.2009.07.013

[24] Noir, J., Jacques, E., Be’kri, S., Adler, P.M. and King, G.C.P. (1997) Fluid Flow Triggered Migration of Events in the 1989 Dobi Earthquake Sequence of Central Afar. Geophysical Research Letters, 24, 2335-2338.

https://doi.org/10.1029/97GL02182

[25] Miller, S., Collettini, C., Chiaraluce, L., Cocco, M., Barchi, M. and Klaus, B. (2004) Aftershocks Driven by a High Pressure $\mathrm{CO}_{2}$ Source at Depth. Nature, 427, 724-727. https://doi.org/10.1038/nature02251

[26] Antonioli, A., Piccinini, D., Chiaraluce, L. and Cocco, M. (2005) Fluid Flow and Seismicity Pattern: Evidence from the 1997 Umbria-Marche (Central Italy) Seismic Sequence. Geophysical Research Letters, 32, L10311.

https://doi.org/10.1029/2004GL022256

Submit or recommend next manuscript to SCIRP and we will provide best service for you:

Accepting pre-submission inquiries through Email, Facebook, LinkedIn, Twitter, etc. A wide selection of journals (inclusive of 9 subjects, more than 200 journals)

Providing 24-hour high-quality service

User-friendly online submission system

Fair and swift peer-review system

Efficient typesetting and proofreading procedure

Display of the result of downloads and visits, as well as the number of cited articles

Maximum dissemination of your research work

Submit your manuscript at: http://papersubmission.scirp.org/

Or contact ojer@scirp.org 